\title{
Presidential Interactions with Faculty Senates: Expectations and Practices
}

\author{
G. David Gearhart, JD, EdD \\ Professor, Higher Education and Chancellor Emeritus, University of Arkansas, USA \\ E-mail: gdgearh@uark.edu \\ Michael T. Miller, EdD \\ Professor, Higher Education, University of Arkansas, USA \\ E-mail: mtmille@uark.edu \\ Daniel P. Nadler, EdD \\ Vice President for Student Affairs, St. Thomas University, USA \\ E-mail: nadlerdan22@gmail.edu
}

Received: February 12, $2021 \quad$ Accepted: April 10,2020 Published: June 1, 2021

doi:10.5296/jet.v8i1.18297 URL: http://dx.doi.org/10.5296/jet.v8i1.18297

\begin{abstract}
Shared governance is an important element in higher education decision making. Through the joint decision making process, faculty members are provided an opportunity to help shape the future of an institution while increasing support for decisions that are made. Presidents, those leaders who are legally bound to guide their institutions, must find ways to collaborate effectively with faculty members in making decisions, and the first step in this process is understanding when and how presidents and faculty leaders interact. In the current study, a national sample of college presidents reported their preparation for the presidency, their perceptions of the functions of a faculty senate, and ultimately, the locations for important interactions between presidents and faculty senates. Results indicated that presidents, regardless of their preparation, found official functions to be the most important for communicating, although, those presidents with academic backgrounds were more likely to perceive faculty senates as having a role in all aspects of an institutions management.
\end{abstract}

Keywords: Decision making; college presidents; faculty senate; collaboration; role definition; college faculty

\section{Introduction}

The role of the American college presidency continues to evolve, increasingly incorporating varied elements of responsibility of institutional management. Once primarily focused on the 


\section{Macrothink

academic operation of an institution, the role has changed to incorporate all of the businessrelated and public agency operations of an institution. This means that the modern college president must be capable of persuasively talking to legislators and donors, as well as students taking classes and the faculty who teach them. In addition to these dimensions, the contemporary college president must also be an expert on state and federal compliance issues, and must have the talent to steer marketing and public relations activities in a persuasive manner.

The presidency is not alone in its evolution, as the contemporary faculty member has also evolved greatly over the past several decades. In addition to content mastery and expertise in the platforms necessary to effectively teach learners, faculty members must be adept at new and varied software platforms that enable them to communicate with learners, their institutions, and to navigate the supporting technology to simply manage their own careers. In addition to these skills, faculty members must also comply with a growing perspective on faculty accountability measures that include everything from monitoring grades awarded to how many times an individual publication has been read, cited, or downloaded. The result is the increasingly managed profession of the professoriate.

A constant in higher education that has differentiated it from business and industry is the management concept of consensus development. Consensus includes the process of faculty members, as the front line of employees on a college campus, having some access and input to decision making, and that this input is valued by the senior institutional leaders who ultimately make the decision (Rosser, 2003). In practical terms, this means that college presidents listen to faculty when they make important decisions. The reward systems and managerial behavior of higher education as of late, however, has detracted from the ability of institutions to effectively engage in building consensus among employees. Instead, often decision making is conducted in a manner that places the fiscal and liability interests of the institution ahead of the concerns of faculty members.

Based on the emerging growth of the business-centered leadership approach of college presidents, the purpose for conducting the study was to identify how contemporary college presidents view their relationship, and the role of, their institution's faculty senates. By clarifying how and what college presidents see as the value of faculty senates, there is a greater likelihood of creating a system that has authentic outcomes and expectations for this relationship.

\section{Background of the Study}

Colleges and universities frequently make use of formal shared governance organizations, and some approximations have indicated that nearly two-thirds of all colleges and universities have some form of 'faculty senate' (Gilmour, 1991; Mortimer \& McConnell, 1991), including community colleges (Cloud, 2018). The title of these organizations vary widely, as some institutions clarify the role of shared governance to academic matters, and consequently have 'academic senates,' and others modify wording to have 'faculty councils.' These organizations also vary widely in their activities, with some bodies distributing money or controlling budgets, and others focusing their work on approving academic courses. Regardless of their titles or 


\section{Macrothink

their origins, faculty governance bodies play an important role, serving as the collective to voice faculty concerns and ideas about the behaviors and activities of an institution (Miller, 1999).

Although faculty governance bodies are believed to be important in contributing to the decision making of an institution, there is little evidence to suggest that they are efficient or highly effective in assisting decision making outcomes. Critics of shared faculty governance often point to the inability of faculty bodies to be efficient in gathering input and offering creative solutions for the welfare of the entire campus as compared to individual unit preferences (Schoorman, 2018). Additionally, the lack of engagement of the strongest faculty members has at times also been a criticism of the governance unit, arguing that the best and brightest faculty are more focused on their own teaching and research than on shared governance meetings. The result has been an increasingly silo-based life for faculty members who see individual (or individual departmental) good as the object of their service (Burgan, 2006).

Faculty senates undertake a wide range of issues and address varied problems and issues on their campuses. At one community college, the faculty senate spent a great deal of effort and energy talking about the removal of the confederate flag and about allowing tobacco use on campus (Armstrong, 1999). In a recent multi-case study analysis of faculty and student senates, researchers (Miller \& Nadler, 2019) found a range of disjointed topics debated and discussed. Institutional financial standing was a common topic, as were curricular issues, but there were also a broad array of topics that ranged from cocktail parties and senate self-interest business affairs to bullying, guns on campus, and library book additions. A key finding from these case studies was the lack of long-term structured discussions or agenda items, and that rarely were these discussion items consistent with the agendas of student governments on their campuses.

The college presidency is uniquely situated alongside the faculty senates on their campuses. The contemporary presidency has changed and evolved in both two- and four-year institutions (Morris, 2017), and the nature of the president's work is increasingly complex (Plinske, 2008). Presidents must be able to communicate effectively with their campus and off-campus constituents, they must have a strong understanding of how technology is changing their work and their worlds (Gearhart, Abbiatti \& Miller, 019), legislative affairs, fundraising, corporate employer relationships, a strong understanding of legal dimensions to decision making, and at the heart of their entire presidential role, they must be fully committed to students and their success. How president's engage in consensus development, then, is both an art and science for the effective leader (Ehrenberg, 2004).

As college presidents increasingly come from non-academic backgrounds (Braswell, 2006), these leaders must work in different ways to connect with their faculty colleagues. This means that they must embrace the 'inefficiencies' of shared governance in order to benefit from the critical dialogue that can come from many voices speaking out on different issues. Miller (1999) referred to three levels of shared governance, including non-participation, tokenism, and ultimately, faculty power. The interrelationship between these levels of negotiated power and authority are important to understand as campus leaders work to move their institutions in the directions that they believe are most needed. And ultimately, understanding how college presidents interact with the shared governance bodies on their campus will provide important 
insights and even suggest strategies for effective and meaningful collaborative governance.

\section{Research Procedures}

To address the purpose for conducting the study, the researchers developed a 23-item survey instrument based on their collective previous research and that of other scholars to administer to college presidents. The survey instrument included an opening three-item section requesting information on the preparation and pathway of the respondent. The second section included the identification of 10 functions of the faculty senate, and asked respondents to indicate their level of agreement that each was an important function of the senate. The third section asked responding presidents to identify their perceived importance of different interactions between college presidents and faculty senates. A first draft of the survey was reviewed by a panel of mid-career professionals and it was modified for word choice and structure. A second version of the survey was given to a panel of five sitting college presidents not involved in the study, and again, clarifying revisions were made to the survey. A third version of the survey was provided to a group of three college presidents and through verbal feedback, finalized. The responses to the data collection were reviewed using a Cronbach alpha, and the identified level of .6832 was determined to be sufficient for the exploratory nature of the study.

The sample for the study included 100 sitting college presidents at comprehensive and research universities. These individuals were randomly selected from an inclusive list of US college presidents using a random number generator. A limitation of the study was that there are differences in the role and functioning of comprehensive and research universities, and that this sample selection technique did not control for those differences. Future research projects of this nature may wish to consider those types of differences.

The instrument was distributed during the summer of 2019 using an electronic survey construction and distribution tool. Sample members first received an email announcing the survey, and three days later received the survey. After six days, a second email reminder was sent to non-respondents, and then six days after that another reminder and invitation to participate was sent to non-respondents. After the first distribution of the survey, 26 presidents fully completed the survey. After the first reminder was sent, and addition 14 surveys were completed, and after the third survey reminder was sent, another 11 presidents completed the survey $(n=51)$. As the study was intended to be descriptive, the $51 \%$ response rate was determined to be acceptable, although study results should be interpreted and generalized with caution due to the low response rate.

\section{Study Findings}

Of the 51 responding college presidents, 47 (92\%) held a doctoral degree, and as shown in Table 1, 2 held a bachelors/masters degree and 2 held professional degrees, such as a law or medical degree. Just over two-thirds of the respondents $(n=39 ; 76 \%)$ arrived at their presidency from an academic pathway, meaning that they had served as a provost or dean immediately prior to their presidential position. Five presidents reported that they came to their position from another internal leadership position on campus, including student affairs $(n=2)$ and development $(n=3)$, and 7 presidents reported that the position they held immediately prior to the presidency was outside of higher education $(n=7 ; 14 \%)$. Nearly a fifth of the presidents had 


\section{Macrothink Institute ${ }^{\text {m }}$}

been in office less than 5 years $(n=9 ; 18 \%)$ with an equal number having served 10 or more years $(n=9 ; 18 \%)$. The majority of responding presidents $(n=33 ; 65 \%)$ had served in their roles 5-to-10 years.

TABLE I. Characteristics of Responding Presidents

$\mathrm{N}=51$

\begin{tabular}{|c|c|c|}
\hline Characteristic & $\mathrm{N}$ & $\%$ \\
\hline \multicolumn{3}{|l|}{ Highest degree earned } \\
\hline Bachelors/Masters & 2 & $4 \%$ \\
\hline Professional (JD, MD) & 2 & 4 \\
\hline Doctoral & 47 & 92 \\
\hline \multicolumn{3}{|l|}{ Pathway } \\
\hline Academic/Provost & 39 & 76 \\
\hline Student affairs & 2 & 4 \\
\hline Development & 3 & 6 \\
\hline Business/Industry & 2 & 4 \\
\hline Military & 0 & 0 \\
\hline Political & 2 & 4 \\
\hline Other & 3 & 6 \\
\hline Years in Service & & \\
\hline
\end{tabular}




\begin{tabular}{|l|l|l|}
\hline Less than 5 & 9 & 18 \\
\hline $5-10$ Years & 33 & 65 \\
\hline More than 10 years & 9 & 18 \\
\hline
\end{tabular}

The profile of the presidents was important to provide context to understanding the perceived primary functions of faculty senates that was included in the second section of the survey. Responding presidents were asked to rate their agreement with the primacy of each of the identified functions of a faculty senate (see Table 2). As a group, on a 1-to-5 Likert-type scale, with 5 representing Strongly Agree and 1 representing Strongly Disagree (progressively), there was agreement that all ten items were primary functions of faculty senates. The highest levels of agreement were reached on the functions of curricular management ( $\bar{x}=4.89$, SD .3097), managing the faculty handbook and policies ( $\bar{x}=4.75$; SD .5317), protecting the campus' culture ( $\bar{x}=4.72$; SD .2000), providing a check and balance to the 'executive' (aka, campus president) branch of campus ( $\bar{x}=4.71 ; \mathrm{SD} .3852$ ), serving as the collective voice of the faculty $(\bar{x}=4.70 ;$ SD .2800), and protecting faculty welfare and interests ( $\bar{x}=4.70$; SD .4774).

Separating the functional areas of the faculty senate by type of presidential experiences provided a different view of what respondents perceived senates should be undertaking. The mean ratings from the presidents with an academic background, as evidenced by having served as a provost or dean, were all in the Agree to Strongly Agree (4-to-5 on the Likert-type scale) range, with only one item, advising senior campus leadership $(\bar{x}=4.45)$ having an agreement level below 4.5. Similarly, those presidents with a background in non-academic campus leadership had responses with mean ratings for all items between 4.0 and 5.0, yet their overall mean agreement on the item of faculty senate as the collective voice of the faculty had a $\bar{x}=4.01$, suggesting a different view of this function than the $\bar{x}=4.88$ of the presidents who had been provosts or deans. For the presidents with backgrounds outside of higher education, three items had agreement levels below 4.0 (Agree), including budget review $(\bar{x}=3.90)$, advising senior campus leadership $(\bar{x}=3.89)$, and providing an executive check-and-balance function $(\bar{x}=3.85)$. This group of presidents agreed most strongly with the curricular management function of the senate $(\bar{x}=4.32)$.

TABLE II. Perceived Primary Functions of Faculty Senates

$\mathrm{N}=141$

\begin{tabular}{|l|l|l|l|l|l|}
\hline Function & Academic & Internal & External & All & SD \\
\hline & $n=39$ & $n=5$ & $n=7$ & & \\
\hline
\end{tabular}




\section{Macrothink}

\begin{tabular}{|l|l|l|l|l|l|}
\hline Curricular Management & 4.99 & 4.90 & 4.32 & 4.89 & .3097 \\
\hline Faculty handbook/ policies & 4.93 & 4.11 & 4.27 & 4.75 & .5317 \\
\hline Campus culture & 4.90 & 4.22 & 4.10 & 4.72 & .2000 \\
\hline Executive check/balance & 4.90 & 4.44 & 3.85 & 4.71 & .3852 \\
\hline Voice of the faculty & 4.88 & 4.01 & 4.25 & 4.70 & .2800 \\
\hline Faculty welfare/interest & 4.85 & 4.35 & 4.12 & 4.70 & .4774 \\
\hline Budgetary review & 4.85 & 4.37 & 3.90 & 4.67 & .1993 \\
\hline Protection of academic interests/policy & 4.67 & 4.11 & 4.03 & 4.52 & .5539 \\
\hline Planning & 4.60 & 4.21 & 4.00 & 4.48 & .4971 \\
\hline Advise senior campus leadership & 4.45 & 4.16 & 3.89 & 4.34 & .2603 \\
\hline
\end{tabular}

As shown in Table 3, responding presidents were asked to identify the location of important interactions between presidents and the faculty senates. Notably, 'faculty senates' could refer to either the formal body as it meets, or, leaders of this group. Overall, responding presidents agreed most strongly that they perceived interacting with these body's during their meetings or deliberations as important $(\bar{x}=4.88$; SD .2822), followed by meetings with the entire faculty $(\bar{x}=4.87$; SD .4289) collaborations with faculty/staff/students ( $\bar{x}=4.80$; SD 1.002), informal meetings/interactions ( $\bar{x}=4.79$; SD .2300), and individual meetings ( $\bar{x}=4.74$; SD .500). As an overall group, there was the lowest level of agreement on interactions surrounding budget approvals $(\bar{x}=4.39$; SD .2610) and personnel actions (4.32; SD .2938).

TABLE III. Perceived Important Interactions of Presidents with Faculty Senates

\begin{tabular}{|l|l|l|l|l|l|}
\hline Function & Academic & Internal & External & All & SD \\
\hline & $n=39$ & $n=5$ & $n=7$ & & \\
\hline Senate meeting/deliberations & 4.99 & 4.56 & 4.50 & 4.88 & .2822 \\
\hline All-faculty meetings/events & 4.96 & 4.40 & 4.75 & 4.87 & .4289 \\
\hline
\end{tabular}




\section{Macrothink}

Journal of Education and Training

ISSN 2330-9709

2021, Vol.8, No.1

\begin{tabular}{|l|l|l|l|l|l|}
\hline $\begin{array}{l}\text { Collaboration with } \\
\text { faculty/staff/students }\end{array}$ & 4.91 & 4.37 & 4.50 & 4.80 & .1002 \\
\hline $\begin{array}{l}\text { Informal interactions } \\
\text { Individual meetings }\end{array}$ & 4.79 & 4.62 & 4.98 & 4.79 & .2300 \\
\hline $\begin{array}{l}\text { Committee metings/ } \\
\text { functions }\end{array}$ & 4.90 & 4.55 & 4.00 & 4.76 & .5000 \\
\hline Official functions & 4.75 & 4.25 & 4.00 & 4.71 & .3888 \\
\hline Executive cabinet meetings & 4.85 & 4.70 & 4.50 & 4.71 & .1117 \\
\hline Budget approvals & 4.65 & 3.99 & 3.70 & 4.60 & .1039 \\
\hline Personnel actions & 4.50 & 4.10 & 3.50 & 4.32 & .2938 \\
\hline
\end{tabular}

Half of the locations of interactions between faculty senates and presidents had very strong levels of agreement when rated solely by the presidents who had served in the provost or dean position. These included senate meetings/deliberations $(\bar{x}=4.99)$, all-faculty meetings $(\bar{x}=4.96)$, collaborations with faculty/staff/students $\bar{x}=(4.91)$, individual meetings $(\bar{x}=4.90)$, and committee meetings and functions $(\bar{x}=4.90)$. Presidents who had served in non-academic higher education positions agreed most strongly with the interaction locations of official functions $(\bar{x}=4.70)$, informal interactions $(\bar{x}=4.62)$, and senate meetings/deliberations $(\bar{x}=4.56)$. And, presidents who came from non-higher education backgrounds agreed most strongly with the interaction locations of informal interactions $(\bar{x}=4.98)$, all-faculty meetings/events $(\bar{x}=4.75)$, and official functions $(\bar{x}=4.50)$.

\section{Discussion}

The initial demographic reporting of respondents suggests that there continues to be a traditional approach to filling college presidencies. The pathway to the presidency through a traditional academic career and time in a provost position was the dominant career progression of those participating in the study, and their predisposition to encourage research activities might well have been a reason that so many of the respondents came from such a background. These responses also illustrate that the majority of respondents had served as a president for at least 5 years, meaning that they are serving beyond their initial appointments. This 'settling into' their roles as president might mean that they are more comfortable taking on challenges and gathering input into decision making, or conversely, it might lend credence to the study findings that they generally do value faculty input into decision making.

The functions of faculty senates varied across pre-presidency experiences, with those 


\section{Macrothink

presidents who had been provost or dean agreeing more strongly than others about all of the roles of the senates. Their strong ratings of agreement about the academic-focus of the senate confirms the use of the senate as a place for faculty work to be housed. Conversely, those coming from outside of higher education to the presidency viewed the senates differently, notably that they had less of a role checking the executive functions of campus, reviewing budgets, or advising senior campus leaders. Those with higher education service outside of academic affairs had relatively consistent agreement levels as those with academic backgrounds, suggesting that the internal culture of the academy clearly places value on certain activities, such as faculty involvement in governance.

The locations of presidential and senate interaction largely mirrored the response patterns of the functions of the senates, with generally strong agreement with each of the interaction locations and higher ratings of agreement for academically-prepared presidents as compared to leaders coming from non-higher education environments. The interaction locations bridged both the formal (senates, faculty meetings, official functions, etc.) as well as the informal, suggesting that regardless of the type of interaction, the roles between the president and senate are defined and carry weight. In a sense, these ratings seem to confirm that official roles never subside, and that a president is in an official capacity at all times.

Taken as a group, these findings prompt a further discussion of what faculty senates are and can be doing to stake their claim as an important part of the shared governance process in the academy. As long as regional accrediting bodies continue to require broad-based, inclusive decision making and the AAUP continues to advocate for shared authority, attempts to define what can and should fall within the realm of shared governance will be a question for leaders and policy makers to consider.

\section{References}

Armstrong, W. P. (1999). Trends and Issues of a Community College Faculty Senate: The Jefferson State Case Study (Doctoral Dissertation). University of Alabama, Tuscaloosa, AL.

Braswell, K. H. (2006). A Grounded Theory Describing the Process of Executive Succession at Middle States University (Doctoral Dissertation). University of Arkansas, Fayetteville, AR.

Burgan, M. (2006). Whatever Happened to the Faculty. Baltimore, MD: Johns Hopkins University Press.

Cloud, R. (2018). Governance in Community Colleges: Legal and Policy Issues. Paper presentation at the Annual Meeting of the Council for the Study of Community Colleges, Fort Worth, Texas, April 2018.

Ehrenberg, R. G. (2004). Governing Academia. Ithaca, NY: Cornell University Press.

Gearhart, G. D., Abbiatti, M. D., \& Miller, M. T. (2019). Higher education's cyber security: Leadership issues, challenges and the future. International Journal on New Trends in Education and Their Implications, 10(2), 11-18.

Gilmour, J. E. (1991). Participative Governance Bodies in Higher Education: Report of a National Study. In R. Birnbaum (Ed.), Faculty in Governance: The Role of Senate and Joint 


\section{Macrothink

Decision Making, New Directions for Higher Education Number 75 (pp. 27-40). San Francisco, CA: Jossey Bass.

Miller, M. (1999). Conceptualizing Faculty Involvement in Governance. In M. Miller (Ed.), Responsive Academic Decision Making (pp. 3-28). Stillwater, OK: New Forums Press.

Miller, M., \& Nadler, D. (2019). Student and Faculty Senate Agenda Alignment: A Test of Comprehensive Shared Governance. Journal of Higher Education Management, 34(1).

Morris, A. (2017). Challenges and opportunities facing the community college president in the 21 st century. Journal of Research on the College President, 1(1), 2.

Mortimer, K., \& McConnell, T. R. (1991). Process of Academic Governance. In M. Peterson (Ed.), Organization and Governance in Higher Education (4th edition, pp. 164-174). Neeham Heights, MA: Simon and Shuster.

Plinske, K. (2008). The Next Generation of College Presidents: Critical Characteristics, Competencies, and Professional Experiences (Doctoral Dissertation). Pepperdine University, Malibu, CA.

Rosser, V. J. (2003). Historical Overview of Faculty Governance in Higher Education. In M. T. Miller, \& J. Caplow (Eds.), Policy and University Faculty Governance (pp. 3-18). New York, NY: Peter Lang.

Schoorman, D. (2018). The Erosion of Faculty Governance. In J. DeVitis \& P. A. Sasso (Eds.), Colleges at the Crossroads, Taking Sides on Contested Issues (pp. 237-251). New York, NY: Peter Lang Publisher.

\section{Copyright Disclaimer}

Copyright reserved by the author(s).

This article is an open-access article distributed under the terms and conditions of the Creative Commons Attribution license (http://creativecommons.org/licenses/by/3.0/). 